\section{Uma rodada de perguntas com os membros do Grupo de Trabalho Linguagem e Tecnologias (ANPOLL)}

A round of questions with members of Grupo de Trabalho Linguagem e Tecnologias (ANPOLL)

Fabiana Cristina Komesu (D) 9

fabiana.komesu@unesp.br

Universidade Estadual Paulista - UNESP

Kyria Rebeca Finardi (D) 9

kyria.finardi@gmail.com

Universidade Federal do Espirito Santo - UFES

Marcelo El Khouri Buzato (D) 9

marcelo.buzato@gmail.com

Universidade Estadual de Campinas - Unicamp

\section{Raquel da Cunha Recuero (D) 9}

raquelrecuero@gmail.com

Universidade Federal de Pelotas

\section{Roberta Varginha Ramos Caiado (D) 9}

caiado.roberta@gmail.com

Universidade Católica de Pernambuco - Unicap

\section{Robson Santos de Oliveira (iD) 0}

robssantoss@yahoo.com.br

Universidade Federal Rural de Pernambuco - UFRPE

\section{Rodrigo Camargo Aragão (iD) 9}

aragaorc@gmail.com

Universidade Estadual de Santa Cruz - UESC

\section{Rodrigo Esteves de Lima Lopes (i) 9}

rll307@unicamp.br

Universidade Estadual de Campinas - Unicamp

\section{Suzi Marques Spatti Cavalari (i) $\mathbf{0}$}

suzi.cavalari@unesp.br

Universidade Estadual Paulista Júlio de Mesquita Filho - UNESP

\section{Valdir Silva (iD) 0}

ollule4@yahoo.com

Universidade do Estado do Mato Grosso - UNEMAT

\section{Vilson Leffa iD 9}

leffav@gmail.com

Universidade Católica de Pelotas - UCPEL

\section{Linguagęm Foco}

Revista do Programa de Pós-Graduação em Linguistica Aplicada da UECE

FLUXO DA SUBMISSÃO

Submissão do trabalho: 14/07/2020 Aprovação do trabalho: 10/08/2020 Publicação do trabalho: 25/09/2020

COMO CITAR

KOMESU, Fabiana Cristina et al. Uma rodada de perguntas com os membros do Grupo de Trabalho Linguagem e Tecnologias (ANPOLL). Revista Linguagem em Foco, v.12, n.2, 2020. p. 370 - 406. Disponível em: https://revistas.uece.br/index. php/linguagememfoco/article/ view/3859.
Distribuído sob

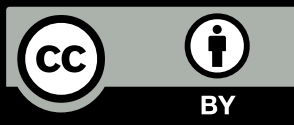




\title{
Resumo
}

Este texto é resultado de uma entrevista feita pela revista Linguagem em Foco com pesquisadores do Grupo de Trabalho (GT) Linguagem e Tecnologias, da Associação Nacional de Pós-Graduação e Pesquisa em Letras e Linguística (ANPOLL). Propusemos, por e-mail, uma rodada de três perguntas a todos os pesquisadores do GT. As perguntas foram as seguintes: (1) a partir da sua perspectiva de estudos e pesquisas, o que você diria que falta sabermos sobre as relações entre linguagem e tecnologia? Em outras palavras, que lacunas teóricas, metodológicas e/ou práticas faltam ser preenchidas?; (2) quão longe ou perto estamos de preencher essas lacunas? De que precisamos para preenchê-las?; (3) em que os conhecimentos adquiridos com as pesquisas mencionadas ajudariam a área de Linguagem e Tecnologia, o professor, o aluno, enfim, o cidadão? Dos vinte e seis pesquisadores que compõem o GT, obtivemos a resposta de onze professores. As respostas foram organizadas em ordem alfabética e dispostas abaixo de cada pergunta de forma sequencial. As discussões compiladas nesta entrevista nos dão a dimensão das atuais pesquisas que estão sendo feitas na área de Linguagem e Tecnologia.

Palavras-chave

Linguagem e tecnologias; pesquisas, teorias; metodologias; ensino.

\begin{abstract}
This text is the result of an interview conducted by the magazine Linguagem em Foco with researchers from the Language and Technologies Working Group (WG), from the National Association of Graduate Studies and Research in Letters and Linguistics (ANPOLL). We proposed, by e-mail, a round of three questions to all GT researchers. The questions were as follows: (1) from your perspective of studies and research, what would you say we lack to know about the relationship between language and technology? In other words, what theoretical, methodological, and / or practical gaps remain to be filled? (2) how far or how close are we to filling these gaps? What do we need to fill them? (3) in which the knowledge acquired with the mentioned researches would help the Language and Technology area, the teacher, the student, in short, the citizen? Of the twenty-six researchers who make up the WG, eleven teachers responded. The answers were organized in alphabetical order and arranged below each question in a sequential manner. The discussions compiled in this interview give us the dimension of the current research that is being done in the Language and Technology area.
\end{abstract}

Keywords

Language and technologies; research, theories; methodologies; teaching.

\section{Apresentação}

O Grupo de Trabalho (GT) Linguagem e Tecnologias da Associação Nacional de Pós-Graduação e Pesquisa em Letras e Linguística (ANPOLL) foi formado em maio de 2010 e reúne, atualmente, 26 linguistas de diversas regiões do país que pesquisam temas relacionados à interface entre linguagem e tecnologias.

Interessada em obter um panorama das questões e preocupações que têm motivado as pesquisas linguísticas relacionadas à presença das tecnologias digitais em nosso cotidiano, a equipe organizadora do número especial' "Linguagens e tecnologia: ideias e debates sobre apropriação tecnológica na escola contemporânea" (volume 12, número 2, ano 2020) da revista Linguagem em Foco encaminhou aos membros do GT da ANPOLL três perguntas por e-mail. Onze pesquisadores do GT responderam aos questionamentos propostos.

As respostas nos mostram diferentes interesses de pesquisas relaciona-

1 Os organizadores do número especial foram Débora Hissa (UECE), Luiz Fernando Gomes (UFAL) e Nukácia Araújo (UECE). 
das ao ensino-aprendizagem-uso de línguas mediado por tecnologias, incluindo a multimodalidade, usos de dispositivos móveis e aplicativos. Esses temas ganham novas características como afetividade nas relações interpessoais midiatizadas, estratégias computacionais utilizadas para disseminar e legitimar discursos, além de demonstrarem clara preocupação com demandas do cotidiano que já nos envolve, como a datificação, os novos usos da inteligência artificial e as novas concepções do sujeito humano.

A fim de facilitar a leitura das reflexões feitas pelos nove professores, organizamos as respostas por ordem alfabética a partir dos nomes dos membros do GT. Participaram da entrevista os seguintes professores: Fabiana Komesu (Unesp); Kyria Rebeca Finardi (UFES), Marcelo El Khouri Buzato (Unicamp), Raquel da Cunha Recuero (UFRGS), Roberta Varginha Ramos Caiado (Unicap), Robson Santos de Oliveira (UFRPE), Rodrigo Camargo Aragão (UESC), Rodrigo Esteves de Lima Lopes (Unicamp), Suzi Marques Spatti Cavalari (UNESP), Valdir Silva (UNEMAT) e Vilson Leffa (UFPel).

As perguntas desta seção de entrevista estão dispostas da seguinte forma: sequenciamos as todas as respotas para a mesma pergunta. Assim todos os nove pesquisadores do GT respondem a mesma pergunta na sequência alfabética pré-estabelecida. Ao final da rodada de perguntas, retomamos a mesma sequência dos respondentes para as demais reflexões. Nas respostas, alguns professores fizeram menção a obras e pesquisas, porém, na seção de referência das entrevistas, incluímos só aquelas que estavam completas.

Tanto as respostas elaboradas pelos professores como as pesquisas que o Grupo de Trabalho Linguagem e Tecnologias vem desenvolvendo mostram a importância dos estudos linguísticos no mundo contemporâneo, especialmente no que se refere às questões atuais e emergentes, as quais nem sempre são bem compreendida ou visualizada pelas pessoas em geral.

Nós da equipe organizadora do número especial da revista Linguagem em Foco agradecemos muito a participação e a valiosa colaboração de todos os professores que gentilmente responderam às perguntas que compõem esta seção de entrevista. Todas as reflexões desenvolvidas com certeza servirão de lume para pesquisadores dos programas de graduação e pós-graduação de todo país. 


\section{Linguagem em Foco - A partir da sua perspectiva de estudos e pesquisas, 0 que você diria que falta sabermos sobre as relações entre linguagem e tecno- logia? Em outras palavras, que lacunas teóricas, metodológicas e/ou práticas faltam ser preenchidas?}

Fabiana Komesu - Os pressupostos teóricos que assumo nos estudos da linguagem privilegiam uma reflexão dialógica sobre linguagem e vida social. Essa visão dialógica implica pensar a linguagem na relação com um seu "exterior constitutivo", o do já-dito, nas palavras de Jacqueline Authier-Revuz, em sua referência a Bakhtin e seu Círculo. Nas investigações sobre as relações entre linguagem e tecnologia, procuro, assim, discutir não apenas o que pode ser tomado como novidade ou inovação - traços comumente atribuídos, no senso comum, ao uso de tecnologias digitais de informação e comunicação -, mas também o que, por vezes, é incorretamente tomado como em estado de saturação porque seria da ordem de uma dimensão histórica, constitutiva da linguagem. O ponto de vista por mim defendido permite, por exemplo,

"Problematizar o processo sócio-histórico de produção de textos multimodais, considerada a dinâmica de transformação e permanência de aspectos linguístico-discursivos, de transparência e opacidade dos sentidos" problematizar o processo sócio-histórico de produção de textos multimodais, considerada a dinâmica de transformação e permanência de aspectos linguístico-discursivos, de transparência e opacidade dos sentidos. É o que tenho procurado discutir nas pesquisas produzidas nos últimos 15 anos, a partir da conclusão de meu doutoramento em Linguística, com a colaboração de colegas pesquisadores do Brasil, França, Suécia: no estudo da relação entre fala e escrita no chamado "internetês" e de memes; no estudo da subjetividade, na relação entre usuário (da linguagem/de tecnologias) e sujeito (da linguagem); no estudo de práticas acadêmicas produzidas em contexto digital e, nos últimos anos, no estudo de letramentos digitais/midiáticos no processo de informação/desinformação, das fake news como notícias falsas ou enganosas em redes sociais. Como se pode ver, o que está na base de minha reflexão é uma temática sobre a qual falta conhecer quase tudo, não só do ponto de vista de como compreender a relação linguagem/tecnologia e de como intervir nessa relação com ações efetivas na sociedade - por exemplo, na educação "em linguagem-e-tecnologia" - mas também, do ponto de vista da atividade científica, particularmente, quanto a aspec- 
tos teórico- metodológicos que envolvam o tratamento multissemiótico como resposta à conjunção do material linguístico com outras semioses mobilizáveis pela tecnologia. É o que busco, por exemplo, ao procurar dar conta da "lacuna" deixada a descoberto pelo fato de que a novidade da tecnologia - quase sempre associada a progresso e desenvolvimento, com promessa de mobilidade social ascendente, de interação com o outro, sem barreira geográfica e sem conflitos (ou, pelo contrário, tendo de enfrentar muitos, em polarização ideológica) - não traz consigo a qualificação de sua inserção numa ordem social e histórica, esta também em permanente dinâmica de transformação, embora tornada mais visível, talvez, quando dos desdobramentos reconhecidamente insaturados do novo.

Kyria Finardi - A maior parte de meu trabalho tem se concentrado na pesquisa sobre o uso/incorporação de tecnologias no ensino-aprendizado-uso de línguas adicionais/estrangeiras (L2). Conforme colocado por nosso colega Ronaldo Gomes em sua fala no evento Applied Linguistics Q \& A Session 1: Technology and Second Language Teaching ${ }^{2}$, modelos de adoção de tecnologias como o de Rogers (2003) com sua classificação de familiarização, utilização, integração, reorientação e evolução, bem como o modelo SAMR (substituição, aumento, modificação, redefinição) de Puentedura têm informado a maior parte dos estudos sobre a incorporação de tecnologias no ensino-aprendizado-uso de L2 embora, ainda segundo Ronaldo, a maior parte tenha uma visão ainda fetichista e instrumental dessa incorporação. Durante a fala do professor Daniel Ferraz (USP) no mesmo evento, vemos que uma visão mais crítica e menos instrumental do uso de tecnologias no ensino-aprendizado de L2 deveria ser concentrar em responder perguntas como Quais tecnologias? Por que? Quando? Onde? Como? Assim, parte do meu trabalho tem se concentrado em analisar o estágio/forma de incorporação de tecnologias no ensino-aprendizado-uso de L2 e outra parte tenta refletir sobre as perguntas "Uma visão mais crítica e menos instrumental do uso de tecnologias no ensino-aprendizado de L2 deveria ser concentrar em responder perguntas como Quais tecnologias? Por que? Quando? Onde? Como?" colocadas por Daniel, com foco especial no potencial das tecnologias para melhorar/facilitar o ensino-aprendizado-uso de L2. Ainda que tenhamos hoje uma quantidade considerável de estudos sobre a incorporação de tecnologias no ensino-aprendizado-uso de $L 2$, especialmente

2 Evento promovido pelo Programa de Pós-graduação em Inglês - PPGI da UFSC em 13 de julho de 2020. 
depois da pandemia, ainda há lacunas a serem preenchidas no tocante ao tipo de ensino-aprendizado-uso promovido por essa incorporação.

Marcelo Buzato - Acredito que o conhecimento em aberto sobre a relação entre linguagem e tecnologias é inesgotável, uma vez que as duas coisas coevoluem; porém, em minha visão, temos algumas novas frentes muito relevantes, que deverão pautar parte das pesquisas no campo aplicado dos estudos da linguagem. Destaco três: a dadificação (datafication); os novos desenvolvimentos e usos da inteligência artificial, em suas diversas modalidades; e, em estreita relação com as duas anteriores, as novas concepções de sujeito humano - ou seja, de falante, leitor/escrevente e aprendiz - que surgem a partir daí. A primeira delas se dá a partir das formas quantitativas e estatísticas de descrição dos comportamentos linguístico-discursivos, do funcionamento dos textos em seus diversos modos semióticos e dos modos de aprender e ensinar (língua, leitura e escrita) pautados em ciência de dados e aprendizagem de máquina. Em segundo lugar, para que os estudos da linguagem, em particular, e as ciências humanas,

"Destaco três: a dadificação (datafication); os novos desenvolvimentos e usos da inteligência artificial, em suas diversas modalidades; e, em estreita relação com as duas anteriores, as novas concepções de sujeito humano - ou seja, de falante, leitor/escrevente e aprendiz que surgem a partir daí." em geral, possam acompanhar essa espiral coevoluliva entre linguagem/cognição/sociedade e tecnologias. Essa nova subjetividade precisa ser pensada em torno de uma nova "unidade básica de análise" para aquilo que chamamos de humano, uma unidade híbrida, ciborgue, por assim dizer, em que as competências, memórias e agências distribuídas entre humanos e máquinas possam ser tratadas colocando-se em suspenso, para algumas finalidades, as clivagens ontológicas entre humano e máquina, natureza e cultura, tecnologia e sociedade, entre outras. Trata- se de um empreendimento em grande parte filosófico, mas que se coloca claramente a partir da relação entre teoria e prática, quando nos detemos qualitativa ou etnograficamente sobre o que está acontecendo nos eventos quotidianos de interação entre humanos e sistemas de informação, ou seja, em como estamos, cada vez mais, tendo que aceitar URAs e robôs como interlocutores em transações, que interferem diretamente em nossa qualidade de vida, em nossas chances de progressão social e em nossa participação cidadã ou, ainda, em como vai se estabelecendo uma nova divisão e hierarquia de trabalho entre as inteligências humanas e artificiais. Isso abrange 
desde traduções automáticas não supervisionadas e recomendações de conteúdos e interlocutores feitas por algoritmos, até tarefas pedagógicas, tais como avaliar e identificar necessidades de aprendizagem de escrita e leitura a partir de produções dos aprendizes por meio de learning analytics. Abrange, ainda, talvez sobretudo, uma nova relação entre corpo e mente, presença e padrão metafísico, expressa no modo como passamos a depender de nossos smartphones, arquivos de nuvem, redes de contato em mídias sociais e assim por diante para nos colocarmos efetivamente no fluxo dos acontecimentos e discursos públicos e privados no cotidiano, ou seja, no que chamamos de "nossa vida" ou "nossa realidade".

Raquel Recuero - Penso que há muito a ser discutido sobre linguagem e tecnologia particularmente dentro dos cruzamentos cada vez mais interdisciplinares destes conceitos. Esta é uma relação que se constitui como cada vez mais complexa, com a criação de "novas" áreas, como a Linguística Computacional, por exemplo, que buscam dar conta desses objetos a partir de vários olhares. As questões também estão mais complexas. Por exemplo, vemos que, nos últimos tempos, discursos desinformativos têm proliferado na nossa sociedade, através de tentativas de manipulação da opinião pública na mídia social. Isso com a participação de bots, inteligência artificial, machine learning e outras estratégias computacionais para criar e legitimar discursos que ressoem com as pessoas. Neste sentido, desvendar as estratégias discursivas utilizadas, para que possamos criar modos de combater a desinformação, é fundamental . Outra questão importante está relacionada também ao espalhamento e legitimação do discurso de ódio ou de discursos tóxicos também por essas ferramentas. Estudar modos de identificar e combater esses discursos também é importante. Claro "Neste sentido, desvendar as estratégias discursivas utilizadas, para que possamos criar modos de combater a desinformação, é fundamental." que tudo isso também passa pelo Letramento Digital, outra área extremamente importante, que relaciona Educação, Linguagem e Tecnologia. Assim, do meu ponto de vista, as relações entre linguagem e tecnologia mostram-se cada vez mais complexas e os grandes desafios são criar métodos/questões e pesquisas que deem conta destes fenômenos.

Roberta Caiado - Sou uma linguista textual, com doutorado em Educação, que se dedica a pesquisar o ensino e a aprendizagem de Língua Portuguesa rela- 
cionados às Tecnologias Digitais da Informação e Comunicação (TDIC). A tecnologia digital para muitos especialistas e a maior parte dos professores, ainda, é entendida como um recurso, uma ferramenta de ensino apenas. Entendo que as TDIC são um meio de ensino/aprendizagem, pois envolvem processos cognitivos complexos e, enquanto meio de ensino/aprendizagem, seu "Acredito que uma lacuna contemporânea consiste na compreensão dos propósitos e efeitos desta relação entre linguagem e tecnologia." uso esporádico em nada favorece o processo de aprendizagem do sujeito aprendente - o aluno. Neste sentido, acredito que uma lacuna contemporânea consiste na compreensão dos propósitos e efeitos desta relação entre linguagem e tecnologia. A busca pelo entendimento das transposições, didática e informática, no meio digital, é outra vertente teórica e, eu afirmaria que, metodológica também, a ser pesquisada, principalmente, diante do inusitado momento advindo da Era Pandêmica ao qual fomos submetidos.

Robson Oliveira - Embora já os PCN (BRASIL, 1998a;1998b) preconizassem o uso das tecnologias em um capítulo específico no opúsculo orientador de Introdução à Língua Portuguesa e, 20 anos depois, a BNCC (BRASIL, 2018) tenha ampliado e incorporado várias das ferramentas tecnológicas do cotidiano social no ambiente escolar como recomendações didático-pedagógicas, observamos sim lacunas ainda existentes tanto teórica quanto metodológicas. Em muitos cursos de licenciaturas de Letras ou mesmo de Pedagogia, observa-se a inexistência de disciplina com enfoque nas tecnologias ou, quando existem em alguns cursos

"Em muitos cursos de licenciaturas de Letras ou mesmo de Pedagogia, observa-se a inexistência de disciplina com enfoque nas tecnologias ou, quando existem em alguns cursos elas estão no campo das disciplinas optativas." elas estão no campo das disciplinas optativas . A disciplina comumente identificada como Introdução à Informática, presente na maioria dos cursos de graduação, tem uma ênfase apenas ferramental, voltada para uso dos recursos de programas e softwares a serem utilizados pelos alunos na graduação como edição de textos, planilhas e gráficos ou apresentação de slides. Poucos cursos dão uma ênfase didático-metodológica ao uso das tecnologias na educação. Temos a impressão de que os profissionais que se interessam ou desejam aprofundar conhecimentos sobre uso das tecnologias edu- 
cacionais deverão recorrer aos cursos de pós-graduação no nível de Especialização. Em paralelo a isto, temos observado na virada do milênio para o século XXI (anos 2000) vários eventos como congressos, seminários, fóruns de educação ou de linguagem que tanto tiveram como tema central a tecnologia ou incluíram mesas temáticas ou grupos de trabalho com foco nas tecnologias da educação. Também deve-se incluir nessa avenida paralela à formação docente os importantes e diversos trabalhos de pesquisadores(as) voltados para essa temática, produzindo literatura direcionada ao uso dos letramentos digitais, cibercultura, literatura nas redes digitais, tecnologias digitais de ensino (GNL, 2000; PRENSKY, 2001; PAIVA, 2001; 2007; SOARES, 2002; KENSKI, 2003; SANTAELLA, 2004; GOMES, 2006; COSCARELLI, 2006; DIONISIO, 2007; 2011; 2014; RIBEIRO, 2007; 2010; 2016; 2018 ; FREITAS, 2009; COSCARELLI; RIBEIRO, 2011; XAVIER, 2011; BEZERRA, 2011; VAN LEEUWEN, 2011; ROJO, 2012; COSCARELLI et al., 2016; OLIVEIRA, 2019).

Rodrigo Aragão - Sempre fui fascinado pela atividade de aprender. Acho que virei professor e pesquisador para nunca sair da aprendizagem. Quando fui estudar Letras, me encantei com a relação da linguagem com a aprendizagem. As duas se provocam mutuamente. Adoro gente e máquinas. Sou filho de bióloga que estudou comportamento de insetos. Por conta de minha mãe, quase fiz Biologia. No curso de Letras, me encontrei com a possibilidade de poder aproximar meu interesse em Biologia dos insetos sociais, com cérebros, linguagem, aprendizagem e máquinas. Acho que, por ter vivido um tempo acompanhando uma entomo-

"Sempre me chamou atenção o papel das emoções nos processos de ensino/aprendizagem de línguas. Tenho buscado aproximar o que faço no campo da formação de professores com pesquisas em linguagem e tecnologias. " logista, especialista em ecologia de insetos - sempre seres sociais, fui sempre desconfiado com a ideia de seres humanos serem entendidos como máquinas computacionais pautados em uma lógica de input-output. Máquinas computacionais são criadas por nós, mas passaram a orientar o modelo hegemônico de cognição, linguagem e aprendizagem desde o século passado. Encontrei na origem das ciências cognitivas, na cibernética de sistemas, e, particularmente, na Biologia do Conhecer de Humberto Maturana e Francisco Varela a distinção sobre máquinas e seres vivos que me ajudou a compreender questões que me instigavam até então. Penso que daqui parte minha primeira aproximação com linguagem e tecnologias. Uma segunda 
aproximação se dá quando percebo as ricas potencialidades que as tecnologias digitais oferecem para transformar os cenários da sala de aula presencial mais centrada no professor e em uma lógica pautada na transmissão de informações, como se professores e estudantes funcionassem como máquinas de igual estrutura, nos termos de teoria matemática da informação de Shannon e Weaver. Daí, a partir dessas aproximações com nosso tema aqui, vejo muitos avanços. Nossa concepção de linguagem tem se transformado recentemente. Temos ferramentas conceituais mais fluídas, sistêmicas e dinâmicas para se compreender inter-relações entre linguagem, aprendizagem e tecnologias. As empreitadas que esfumaçam fronteiras disciplinares têm aumentado e se esforçado cada vez mais para compreender fenômenos complexos como linguagem e tecnologias e suas relações com a aprendizagem de novas línguas. A diversidade de perspectivas teóricas e metodológicas enriquecem cada vez mais a compreensão dos objetos de pesquisa vinculados ao nosso tema que se transformam rapidamente. Sinto como caminhamos dependendo mais e mais de entendimentos teóricos que se vinculam a procedimentos empíricos retroalimentando um ao outro para dar conta de temas sistêmicos vibrantes que vivemos no nosso cotidiano com linguagem e tecnologias. Sempre me chamou atenção o papel das emoções nos processos de ensino/aprendizagem de línguas. Tenho buscado aproximar o que faço no campo da formação de professores com pesquisas em linguagem e tecnologias. Ao compararmos resultados de pesquisa do nosso primeiro biênio em que o objetivo foi fazer um levantamento histórico das pesquisas produzidas no Brasil envolvendo práticas sociais da linguagem mediada pela tecnologia em termos de temas e de metodologia de pesquisa, gostaria de destacar dois temas e metodologias que avançaram. Avançamos com pesquisas enfocando desenvolvimento de habilidades orais em inglês com tecnologias digitais e também enfocando o papel desempenhado pelas emoções aí em comparação com a sala de aula presencial. Ademais, aumentaram os trabalhos com produção de textos orais com tecnologias digitais com tendências inovadoras como aumento considerável de pesquisas-ações com smartphones e experimentos de pesquisa que combinam metodologias quantitativas com práticas qualitativas e que avaliam a disposição comunicativa quando trocamos elementos do sistema em ambientes digitais. Acompanhado a pesquisas nessa linha, houve aumento na produção textual multimodal, mesmo com a continuidade de diversos desafios enfrentados por professores de inglês no uso de tecnologias. As tecnologias digitais móveis têm sido objeto de várias pesquisas interessantes. 
Rodrigo Lima Lopes - A complexidade dessa pergunta se coloca, especialmente, pela forma como a linguagem tem sido encarada no âmbito da Linguística e da Linguística Aplicada, algo que certamente tem implicações teóricas, metodológicas e, por conseguinte, na formação dos profissionais. Primeiramente, tem predominado uma perspectiva de que a linguagem é uma característica inata, relacionada a nossa própria definição de humano. Tal construto leva à equivalência entre os diferentes suportes comunicacionais, algo que se coloca como problemático se pensarmos nas relações que a linguagem estabelece com as demais tecnologias em nossa contemporaneidade. Entretanto, se encararmos a linguagem como um construto tecnológico, uma das diversas máquinas de significar (Flusser, 2007, 2010), a relação entre ela e as demais tecnologias se dá como parte de um ecossistema comunicativo. Consequentemente, ela

"Acredito que a constante datificação da sociedade é um desafio a ser levado em conta, pois ela gera questionamentos sociais importantes." passa a ser um importante processo de construção da realidade, com significados motivados pelos diversos contextos sociais (Kress, 1993). Em segundo lugar, estamos, a cada dia, mais dependentes de plataformas telemáticas (Bridle, 2019; Morozov, 2019), sendo que o entendimento de como a tecnologia influencia nossa percepção da realidade é um passo importante para que alguns mitos sejam derrubados (Bridle, 2019). Entre eles estaria uma nova caverna, uma vez que, como Bridle (2019) coloca, a compreensão de como se dão os processos tecnológicos é relativamente transparente para aqueles que nela atuam e fortemente opaca para os demais. Essa opacidade poderia ora gerar uma espécie de fascínio, uma identificação da tecnologia como algo quase divino, ora levar a uma relação ingênua, na qual as diversas tecnologias seriam identificadas ou como algo neutro, espontâneo, ou mesmo resultado de um processo de evolução natural. É nesse sentido que o estudo das interações possibilitadas pelos diferentes ambientes tecnológicos se coloca como relevante. Todavia, é importante pensar que tais possibilidades não podem ser analisadas sem levar em conta os algoritmos que, recorrentemente, formatam e disponibilizam informações, criando nossa bolha na rede (Noble, 2018; Rieder, 2020). De uma certa forma, nossas manifestações textuais estão condicionadas por esses algoritmos, que determinam aquilo que podemos ver, reforçam comportamentos e ideias, assim como determinam em qual medida podemos ser vistos. Acredito que a constante datificação da sociedade é um desafio a ser levado em conta, pois ela gera questionamentos sociais importantes. Acho que é relevante trazer à baila o status negativo dos processos 
de análise quantitativa ou métodos mistos (quali/quanti). Tais processos não são totalmente reconhecidos por todas as subáreas da Linguística Aplicada, algo que se dá principalmente pela não familiarização com ferramentas de análise e coleta de dados. Tais métodos podem levar a um deslocamento do eixo tradicional que diversas áreas da Linguística Aplicada se encontram, possibilitando a exploração da linguagem a partir de metodologias capa-

"Compreender como nossa interação se dá dentro do fluxo de dados que representa as redes é algo importante para o papel ideológico da linguagem na formação do ser político que hoje habita a internet." zes de oferecer uma descrição mais clara das redes e seus algoritmos. Compreender como nossa interação se dá dentro do fluxo de dados que representa as redes é algo importante para o papel ideológico da linguagem na formação do ser político que hoje habita a internet. Como bem coloca Hoffman (1996), esse processo de datificação constante e mitigação de diáspora (Lévy, 1998) leva não apenas a uma democratização dos movimentos sociais, mas também a possibilidade de radicalizações antidemocráticas, em especial por possibilitar o renascimento do discurso de ódio. No que tange a tais questões, é imprescindível observar que não apenas a linguagem em ambientes telemáticos, mas também todos os metadados a ela relacionados são igualmente importantes.

Suzi Cavalari - Nos últimos anos, venho me dedicando a investigar o processo de ensino-aprendizagem de línguas estrangeiras em telecolaboração, um contexto de intercâmbio virtual que envolve grupos de aprendizes de línguas e países diferentes que se encontram virtualmente a fim de aprenderem línguas por meio da realização de tarefas e com o apoio de um professor. Essa proposta pedagógica pressupõe o uso de diferentes recursos tecnológicos que permitem a comunicação síncrona e assíncrona entre os participantes, tanto na modalidade falada quanto escrita da língua. Pesquisas realizadas no Brasil e no exterior revelam que, do ponto de vista prático, existem inúmeras questões relativas à implementação pedagógica institu-

"O potencial da prática telecolaborativa para a promoção da internacionalização do ensino e da pesquisa, ou alternativas de avaliação que sejam compatíveis com proposta autônoma e colaborativa de ensino-aprendizagem." cionalizada que ainda precisam ser descritas e discutidas como, por exemplo, o 
potencial da prática telecolaborativa para a promoção da internacionalização do ensino e da pesquisa, ou alternativas de avaliação que sejam compatíveis com proposta autônoma e colaborativa de ensino-aprendizagem. Do ponto de vista teórico-metodológico, o saber científico sobre o funcionamento da língua e sobre como se ensinam-aprendem línguas em ambientes mediados por tecnologias sob perspectiva qualitativa tem dominado as propostas de pesquisa em contexto telecolaborativo. Eu diria que as lacunas a serem preenchidas parecem estar ligadas à impossibilidade de se fazerem generalizações a partir de estudos de caso e pesquisas qualitativas com número reduzido de participantes. Preencher essa lacuna depende de promover, dentro da área de Linguística Aplicada e Ensino-Aprendizagem de Línguas, discussões de natureza epistemológica em que se entrelaçam perspectivas quantitativa e qualitativa, incluindo recortes transversais e longitudinais na condução de pesquisas sobre ensino-aprendizagem de línguas estrangeiras em ambientes mediados por tecnologias, de maneira geral, e em telecolaboração, de forma específica.

Valdir Silva - Eu pertenço a um grupo de professores e pesquisadores da Linguística Aplicada que tem como base teórico-metodológica a Teoria dos Sistemas Dinâmicos Complexos que, em linhas gerais, refere-se aos sistemas que se autoconfiguram em razão das adaptações que emergem dos processos de interações produzidos pelos agentes que neles se inserem. Ou seja, sistemas que se marcam pela mudança, uma propriedade que torna muito difícil saber seus comportamentos futuros. Assim, por considerar as relações entre linguagem e

"Por considerar as relações entre linguagem e tecnologia como um sistema de práticas sociais altamente dinâmico e complexo, penso que, mesmo com todas as pesquisas já produzidas, ainda pouco sabemos sobre tais relações." tecnologia como um sistema de práticas sociais altamente dinâmico e complexo, penso que, mesmo com todas as pesquisas já produzidas, ainda pouco sabemos sobre tais relações. As tecnologias - por serem produtos que emergem a todo instante devido à capacidade criativa e inovadora do ser humano exigem que aprendamos e que ensinemos a relacionar com elas de diferentes formas e com diferentes propósitos. Logo, devido a essa dinâmica, penso que cabe a nós compreendermos esses funcionamentos e produzirmos as pesquisas necessárias orientadas por modelos teórico-metodológicos que precisam ser atualizados ou gerados, para tentarmos dar conta do 
desafio científico que conforma o sistema complexo e multifacetado das inter-relações entre práticas sociais da linguagem e tecnologia. Assim, valendo-me da frase de Buzz Lightyear, de Toy Story, sigamos, pois, "ao infinito... e além!".

Vilson Leffa - Teoria é o que não falta para explicar as relações entre linguagem e tecnologia. Temos a Teoria da Atividade, Sistemas Adaptativos Complexos, Teoria do Caos, Teoria Ator-Rede, entre tantas outras. O fundamental, me parece, é como ver a relação entre linguagem e os dispositivos digitais: ver os dispositivos como mediadores ou como agentes? O que queremos? Aplicativos que se-

"Por que não tentar desenvolver aplicativos que sejam não só mediadores, atuando como instrumentos, mas também agentes, atuando como tutores capazes de interagir com o aluno." jam nossos escravos, versão digital do pedagogo grego, tipo Google Assistant, sempre disponível para esclarecer nossas dúvidas? Ou queremos aplicativos que sejam nossos mestres, que, em vez de responder nos façam perguntas, tipo magister rigoroso, avaliando nossas respostas e nos punindo quando erramos? Queremos um aluno que pergunta e um dispositivo que responde ou, ao contrário, queremos um aluno que responde e um dispositivo que pergunta e avalia? Minha resposta, assumidamente ambiciosa, é uma pergunta: por que não as duas coisas? Por que não tentar desenvolver aplicativos que sejam não só mediadores, atuando como instrumentos, mas também agentes, atuando como tutores capazes de interagir com o aluno.

\section{LF - Quão longe ou perto estamos de preencher essas lacunas? De que preci- samos para preenchê-las?}

Fabiana Komesu - Creio que a oportunidade de eleger uma direção de pesquisa e levá-la adiante é o que mais importa quando se pensa em olhar para os resultados em perspectiva futura. A lacunosidade do conhecimento sobre qualquer assunto existe em função também da movência dos próprios fenômenos observáveis. Estabelecer direções de pesquisa e estar atento à dinâmica dos fenômenos observados é, de modo geral, o que se precisa para continuar a preencher lacunas. No que diz respeito à direção de pesquisa que tem orientado o meu trabalho, cito o exemplo da concepção de subjetividade como radicalmente fundada na alteridade constitutiva. Essa ideia tem potencial para auxiliar o pes- 
quisador a diferenciar um usuário da tecnologia - aquele que saberia acessá-la e manipulá-la - do sujeito da linguagem, aquele que, de uma perspectiva discursiva, ocupa, na produção de sentido, uma posição sobre a qual não tem total controle. Em Komesu; Galli (2016), discutimos a produção de efeitos de sentido na chamada disseminação de informação. Essa distinção se liga a outra: a diferença entre linguagem (qualquer que seja, desde que não se limite a um arranjo lógico) e tecnologia (instrumental cuja gênese pode ser descrita pelo homem, cujo uso Ihe é facultado como o de qualquer instrumento e sobre o qual ele pode agir por própria conta).

Kyria Finardi - No artigo "O digital é o novo normal"3, Manuel Castells comenta que a pandemia fez com que entrássemos na sociedade digital na qual já vivíamos sem que houvéssemos assumido isso. Para ele, agora sabemos para que serve a internet, ou seja, para se comunicar, se relacionar e não para se isolar ou alienar. Ainda segundo Castells nesse artigo, a internet não elimina a emoção, mas a alimenta. Não é comida, mas sem os pedidos de comida on-line seria mais difícil comer durante a fase de isolamento social. Castells prevê que não haverá volta atrás na sociedade digital uma vez que o novo normal não será o que conhecíamos antes, mas sim uma realidade que também é virtual. O autor traz dados de 2019 mostrando que passávamos, em média, 5,5 horas por dia online, antes da pandemia. Ou seja, podemos afirmar que já tínhamos entrado na era da comunicação digital antes da pandemia de tal sorte que a transição para novas formas de relacionamento e atividade humana me-

"Ainda que o distanciamento social e essa nova realidade/virtualidade impostas pela pandemia Covid-19 tenham acelerado os processos de migração de várias atividades acadêmicas para o mundo virtual, dentre elas, o ensino-aprendizado-uso de L2, há várias lacunas, principalmente desde o ponto de vista pedagógico e de formação de professores de como fazer, manter ou melhorar essa transição/ permanência no virtual."

diada por tecnologias digitais durante o confinamento foi menos dramática. Isso não significa que a transição para o digital seja menos complexa ou desafiadora ou que a transição para o ensino-aprendizado no formato remoto, seja ele emergencial (como praticado durante a pandemia) ou permanente, como na EaD ou

3 Disponível em https://www.fronteiras.com/artigos/o-digital-e-o-novo-normal?fbclid=IwAR1iTxx5DuuOwpo4CFM3a6leCsfgk5GLOZ6CpGxbL6gjZSaicpLLVIOHng, acesso em 01/06/2020. 
em abordagens híbridas, seja mais tranquilo, desde o ponto de vista pedagógico. Ainda que o distanciamento social e essa nova realidade/virtualidade impostas pela pandemia Covid-19 tenham acelerado os processos de migração de várias atividades acadêmicas para o mundo virtual, dentre elas, o ensino-aprendizado-uso de L2, há várias lacunas, principalmente desde o ponto de vista pedagógico e de formação de professores de como fazer, manter ou melhorar essa transição/ permanência no virtual.

Marcelo Buzato - Quando penso no "nós", pressuposto no "estamos" da pergunta, tenho respostas diferentes para a Linguística Aplicada ou para as Ciências Humanas em geral. Na LA, tenho acompanhado desenvolvimentos recentes na discussão sobre o pós- humanismo, puxados em alguma medida por publicações de autores como Alastair Pennycook; e, no Brasil, ainda que de forma modesta, por mim e alguns de meus alunos, além de outros pesquisadores, muitos dos quais participaram do dossiê "O pós-humano é agora", que editei em 2019 pela Trabalhos em Linguística Aplicada. Não há ainda, contudo, na nossa área, muita ênfase no problema da dadificação dos discursos, da representação visual de dados quantitativos como argumento e função narrativa - um problema que, no fundo, remete a uma longa tradição de pesquisas sobre a relação entre a visão quantitativa e estatística (e agora computacional) do mundo versus a visão narrativo-qualitativo-dialógica que constitui a nossa tradição e o nossos objetos de pesquisa. Tenho alguns alunos estudando letramento de dados e narrativas de dados, mas confesso que não encontrei ainda outros colegas brasileiros da LA empenhados especificamente nesse tema. Ainda assim, penso que esse é um tema urgente, bem como o é o tema dos algoritmos sociais, baseados em metadados de usuários e sua influência nas

"Uma formação suficiente em métodos e linguagens quantitativas do tipo que caracteriza as assim chamadas "humanidades digitais", métodos e técnicas estatísticas e computacionais que nos permitam dialogar com as pesquisas em linguagem e tecnologias feitas pelo campo das ciências exatas, problematizando, mas também contribuindo para que a linguagem desse sujeito ciborgue não represente uma redução e empobrecimento da cognição, da política, das artes, da educação etc. em nome de uma visão computacional do mundo que não seja inquestionável."

4 Disponível em https://periodicos.sbu.unicamp.br/ojs/index.php/tla/issue/view/1590 
grandes "conversas" articuladas em rede, que têm pautado a esfera pública no Brasil na base da influência, muito mais do que na da argumentação e, na base da opinião, muito mais do que na base da referência a evidências. Nesse caso, vejo sim alguns colegas avançando bastante e abrindo caminho para mais pesquisas, entre eles, o meu colega de Unicamp, Rodrigo Lima-Lopes, mas também outros que não estão em departamentos de linguística (aplicada), mas se interessam por nossos temas, como Carlos D'Andrea, da UFMG; e Raquel Recuero, da UFRGS, entre outros. $\bigcirc$ que sinto que mais falta a nós que fazemos Linguística Aplicada, no momento, é, na verdade, uma formação suficiente em métodos e linguagens quantitativas do tipo que caracteriza as assim chamadas "humanidades digitais", métodos e técnicas estatísticas e computacionais que nos permitam dialogar com as pesquisas em linguagem e tecnologias feitas pelo campo das ciências exatas, problematizando , mas também contribuindo para que a linguagem desse sujeito ciborgue não represente uma redução e empobrecimento da cognição, da política, das artes, da educação etc. em nome de uma visão computacional do mundo que não seja inquestionável. Isso não é para que reproduzamos as pesquisas deles, necessariamente, mas justamente para entender como se constrói essa hegemonia do quantitativo, do algoritmo e do metadado nas concepções de linguagem, sujeito, texto, interpretação, sentido, etc. no lado de lá. E, claro, para entender quais oportunidades há nisso tudo para as humanas, ao menos aquela parte das humanas "pós-humanista", que se apega aos valores de humanidade, ética, justiça, etc., mas não se apega a visões do humano que talvez já não nos permitam avançar na "humanização" do mundo. Nós, francamente, temos uma atitude, em geral, negativa com relação a essas visões e métodos quantitativo-estatístico-computacionais, temos dificuldade em chamar "ciência de dados" de Ciência, mas hoje não podemos ficar simplesmente no campo dos efeitos da implantação dessa visão na infraestrutura semiótica da sociedade. É preciso que entendamos as externalidades disso antes que apareçam e que possamos ser tão críticos quanto propositivos, capazes de influir nesses desenvolvimentos tecnológicos, saindo das clássicas posições de críticos ferrenhos ou deslumbrados tecnológicos que costumam nos restar depois que tudo foi decidido e implementado por outrem, mas nos parece ter sido um "advento" neutro.

Raquel Recuero - Acho que ainda estamos bem longe, particularmente no Brasil. Para preencher essas lacunas, creio que é preciso mais interdisciplinaridade, mais apoio às ciências humanas, sociais e mais diálogo. Não vejo isso atualmente. 
"É preciso boa vontade política, dos gestores das universidades e mesmo dos pesquisadores. Oportunizar esses diálogos deveria ser chave para grupos de pesquisa e pesquisadores."
É preciso boa vontade política, dos gestores das universidades e mesmo dos pesquisadores. Oportunizar esses diálogos deveria ser chave para grupos de pesquisa e pesquisadores.

Roberta Caiado - O preenchimento destas lacunas, no meu entendimento, é lento e envolvido por medo e precauções, muitas vezes indevidas, sobre o uso das TDIC, principalmente na escola. As reservas com relação à utilização das TDIC superam todos os dados positivos analisados em pesquisas científicas. Porém, ao longo dos anos de pesquisa com esta temática, observo que as práticas de uso questionadas, dessas mesmas TDIC, ampliaram-se de tal forma que se tornou incoerente a separação entre nativo e imigrante digital. A Era Pandêmica, certamente, acelera o preenchimento das lacunas que descrevi na questão anterior e busca compreender,

"A formação do professor que resistia ao uso da tecnologia digital foi providenciada e o suporte para que a infoexclusão fosse amenizada adveio de uma comunidade distante socialmente, mas conectada pela grande rede." com agilidade, os propósitos e efeitos da relação entre linguagem e tecnologia. Observando uma das vertentes imposta pelo isolamento social - a educação observa-se que ações rápidas tiveram que ser implementadas para suprir a lacuna provocada pela falta do ensino presencial, assim, o ensino, totalmente remoto e síncrono, apareceu na maior parte das escolas; a formação do professor que resistia ao uso da tecnologia digital foi providenciada e o suporte para que a infoexclusão fosse amenizada adveio de uma comunidade distante socialmente, mas conectada pela grande rede.

Robson Oliveira - Poderemos dizer que estamos 'nem longe', 'nem perto', estamos no meio do caminho, ressignificando práticas pedagógicas tradicionais com o uso das tecnologias, tornando o ensino híbrido entre o 'analógico' e o digital, no sentido de incluir tecnologias na sala de aula, em laboratório de ensino, em práticas diversas. Desde o uso pedagógico dos smartphones, regulamentando inclusive por legislação educacional específica em alguns estados brasileiros, até a imersão em ambientes virtuais de aprendizagem, temos observando um movi- 
mento amplo neste sentido, mas muito mais 'arrastado' pelas forças sociais que fazem uso das tecnologias do que por uma orientação mais sistemática das agências fomentadoras da educação. O uso de laptops, notebooks, laboratórios de informática, com recursos holográficos inclusive, são mais comuns e visíveis nas escolas privadas. Em decorrência do nível econômico bastante diversificado e apresentando contínuas carências nas diversas regiões do Brasil, não ocorre a mesma equiparação tecnológica nas escolas públicas em relação às escolas privadas. As lacunas existentes precisam ser preenchidas por mais investimentos de infraestrutura tecnológica nas escolas conjuntamente com

"Não adiantaria termos escolas altamente equipadas com tecnologias e docentes sem qualquer formação pedagógica para utilizá-las; do mesmo modo, inversamente, não valeria investir em professores(as) para usar recursos tecnológicos como lousa digital, realidade aumentada, robótica se as escolas não dispõem desses recursos."

\section{a formação docente. Não adiantaria} termos escolas altamente equipadas com tecnologias e docentes sem qualquer formação pedagógica para utilizá-las; do mesmo modo, inversamente , não valeria investir em professores(as) para usar recursos tecnológicos como lousa digital, realidade aumentada, robótica se as escolas não dispõem desses recursos. $\bigcirc$ que observamos é o esforço de muitos docentes, em diversas modalidades, buscando acompanhar o progresso tecnológico, o uso comum das crianças e adolescentes com as tecnologias dominantes na sociedade, a fim de tornarem as aulas motivadoras, atraentes e, principalmente, adequada aos novos tempos de ênfase multiletrada e multimodal.

Rodrigo Aragão - Em colaboração com colegas do Laboratório de Linguagem e Tecnologia, o Lalintec da UFMG, desenvolvi pesquisas sobre o papel das emoções no desenvolvimento de habilidades orais em inglês com tecnologias digitais que vão na direção de preencher algumas lacunas identificadas no cenário nacional principalmente. Já fruto de pesquisas mais recentes, trabalhamos em diversas ações que geraram a produção de e-books com curadoria de ferramentas digitais para o ensino de línguas, e mapeamentos de estado da arte sobre pesquisas em linguagem e tecnologias no ensino de inglês em diversas regiões do país. Essas pesquisas nos mostram como nossos estudos avançaram nessa última década e como seguindo trabalhando coletivamente para preencher lacunas. Na região 
Nordeste, por exemplo, embora as pesquisas continuem a ser predominantemente qualitativas, encontramos um número de estudos baseados na pesquisa-ação colaborativa com diversidade de estratégias de observação-participante on-line e off-line. Há um aumento significativo de pesquisas com escolas buscando colaborações mútuas e com foco na formação de professores com tecnologias móveis. Vemos aumento de estratégias metodológicas quali-quantitativas com foco em produção textual multimodal e interação oral em diferentes ambientes digitais e sites de redes sociais. Embora as pesquisas continuem gerando contextos para experimentação com linguagem e tecnologias, identificamos trabalhos de investigação de políticas públicas de tecnologias digitais e ensino de inglês, na Educação Básica e no Ensino Superior. Esses resultados nos indicam a expansão do uso e de algumas práticas pedagógicas com tecnologias na Educação Básica e no Ensino Superior, mesmo considerando que os desafios de infraestrutura

"Temos nos debruçado em desenvolver estratégias de ensino-aprendizagem com uso do Whatsapp e outros recursos para telefones celulares a fim de lidarmos de alguma maneira com uma comunidade estudantil vulnerável e com uma estrutura de rede e equipamentos que é extremamente precária." e formação de professores permanecem e se tornaram agora mais agudas. Nesse sentido, vejo que há demanda para estudarmos o que está em curso a partir de diversas experiências autênticas de distintas instituições. O desafio que vivemos nesse momento é inigualável. Com apoio o do grupo de pesquisa que coordeno na UESC, temos nos debruçado em desenvolver estratégias de ensino-aprendizagem com uso do Whatsapp e outros

"A emergência de lidarmos com outras formas de ensinar e aprender no berço do capitalismo de vigilância e de algoritmos de governança com aprofundamento do desgaste emocional da profissão docente são desafios que demandam trabalho conjunto para seguir em frente na luta com esperança." recursos para telefones celulares a fim de lidarmos de alguma maneira com uma comunidade estudantil vulnerável e com uma estrutura de rede e equipamentos que é extremamente precária. Nesse momento também estamos imersos na discussão com colegas sobre como dar continuidade às nossas atividades educativas principalmente na graduação e nas escolas. Vejo que os professores estão mais desgastados emocionalmente em nossos contextos cada vez mais imersos em linguagens e tecnologias. Para dar conta 
da complexidade e da amplitude de pesquisas e ações nas quais precisamos nos engajar, o trabalho conjunto e as colaborações de pesquisa são fundamentais. Vejo que as lacunas que sempre existem são mais bem preenchidas nas parcerias. Aprendo muito na colaboração com colegas do Lalintec/UFMG. Levo as experiências de aprendizagem que se abraçam com as atividades do nosso grupo na UESC. O GT de Linguagem e Tecnologias tem um grupo muito rico e tenho acompanhado com interesse as pesquisas e a diversidade de objetos, metodologias e quadro teóricos geram resultados que enriquecem sobremaneira o campo. Fico sempre pensando como não é fácil acompanhar o ritmo das pesquisas nessa área pujante. Sempre há novas lacunas. A partir de experiências vividas no contexto da pandemia do novo coronavírus, precisamos avançar para lidar com agravamentos da profissão docente provocadas pelo contexto de isolamento e cercado de incertezas. A emergência de lidarmos com outras formas de ensinar e aprender no berço do capitalismo de vigilância e de algoritmos de governança com aprofundamento do desgaste emocional da profissão docente são desafios que demandam trabalho conjunto para seguir em frente na luta com esperança.

Rodrigo Lima Lopes - No âmbito do grupo de pesquisa MiDiTeS (Mídia, Discurso, Tecnologia e Sociedade), que coordeno na Unicamp, temos tomado diversas ações para tentar refletir sobre as questões acima mencionadas. Nossos esforços têm se concentrado em três eixos inter-relacionados: 1) Ensino e Literacias, 2) Ativismos e 3) Datificação da sociedade. Uma constante nesses eixos é nossa reflexão sobre como a linguagem se relaciona aos demais processos tecnológicos com que interage. No caso do primeiro, isso passa não apenas por compreender como os hábitos midiáticos/tecnológicos podem interferir na aprendizagem das diversas linguagens, mas também construir um processo de interação no qual a construção da identidade nas diferentes mídias e plataformas é um elemento importante para compreensão do lugar no indivíduo e sua comunidade. Nesse sentido, o aprendizado seria uma consequência de ações e interações midiáticas que seriam o resultado de autorrepresentações e construção de um pensamento crítico dentro do espaço tecnológico. Além disso, trabalhamos na compreensão de como os diferentes percursos de literacia em nossa contemporaneidade levam a formação do indivíduo em espaços constantes de aprendizagem. Em tal contexto, pensamos também o papel da educação aberta e seus recursos em rede. Já o segundo e o terceiro estariam intimamente ligados. Buscamos analisar como os diferentes ativismos em rede e a datificação constante caminham de forma a modelar parte importante de nossa percepção de mundo e da socieda- 
de. Entre as perspectivas que são trabalhadas, estão o midiativismo, o ativismo de dados, a linguagem do ódio, processos de desinformação e os linchamentos virtuais. Em muitos casos, tais pesquisas trazem importantes insumos para nosso primeiro eixo de atividade. Fora do contexto de nosso grupo, trabalhos inspiradores também estão sendo realizados por pesquisadores tanto no contexto da

"Algo que me preocupa bastante nesse contexto é a formação de professores e pesquisadores. Poucas são as discussões teóricas presentes no contexto dos cursos de Letras, sendo que reflexões sobre a análise e tratamento de dados são bastante incomuns, ou mesmo desincentivadas na área. Isso inviabiliza a construção de uma massa crítica, especialmente no que tange a uma literacia de dados ou midiática."
Linguística Aplicada, como é o caso do estudo de questões de Pós-Humanismo pelo Professor Marcelo Buzato, como fora dele, como é o caso do grupo Lab404 que atua na Universidade Federal da Bahia, do grupo R-EST, que realiza estudos redes sociotécnicas na UFMG; e de Raquel Recuero na Universidade Federal de Pelotas. No contexto internacional, gostaria de ressaltar as contribuições realizadas pelo grupo Digital Methods da Universidade de Amsterdã, com especial ênfase ao trabalho de Bernhard Rieder. Todavia, algo que me preocupa bastante nesse contexto é a formação de professores e pesquisadores. Poucas são as discussões teóricas presentes no contexto dos cursos de Letras, sendo que reflexões sobre a análise e tratamento de dados são bastante incomuns, ou mesmo desincentivadas na área. Isso inviabiliza a construção de uma massa crítica, especialmente no que tange a uma literacia de dados ou midiática. Tendo a pensar que isso ocorre porque diversos pesquisadores ainda trabalham com a ideia de uma ciência da linguagem como algo não replicável e que não pode ser contaminada por métodos de análise que não se baseiem exclusivamente na interpretação intuitiva do contexto e alguns poucos dados. Um ponto importante a ser trabalhado nesse contexto geral é a perspectiva de inserção dos estudos de nossa área no contexto mais amplo das Humanidades Digitais, uma área multidisciplinar que se utiliza da tecnologia como ferramenta e lócus de análise nas ciências humanas. Claro que algumas áreas da LA já realizam o uso sistemático de computadores, um exemplo importante é a Linguística do Corpus (LC) no qual reconhecemos o trabalho pioneiro de Tony Berber Sardinha na PUC-SP. Entretanto, apesar de ser uma abordagem teórico/ metodológica importante, a LC não tem os processos de interação em rede como 
eixo central de sua discussão.

Suzi Cavalari - Eu diria que estamos a caminho de preencher essas lacunas. $\bigcirc$ surgimento de corpora a partir de dados multimodais coletados em ambientes de aprendizagem mediada por tecnologias é clara evidência desse fato. No cenário brasileiro, destaco o MulTeC (Multimodal Teletandem Corpus) (Aranha; Lopes, 2019), que é resultado de pesquisas realizadas no âmbito do grupo de pesquisa em Teletandem da UNESP - São José do Rio Preto, do qual orgulhosamente faço parte. O corpus se constitui de gravações de interações orais entre aprendizes de inglês e português, entradas de chat, diários de aprendizagem, textos escritos em língua estrangeira, questionários (inicial e final) respondidos pelos participantes em um período de quatro anos. No contexto europeu, saliento o LETEC (LEarning and TEaching Corpus) (Wigham; Chanier, 2013) que reúne quantidade expressiva de dados coletados em ambiente de interação virtual durante um curso de CLIL (Content and Language Integrated Learning). Há traços característicos desses dois exemplares que merecem atenção: (i) a natureza multimodal dos dados, (iii) a metodologia de organização e sistematização que envolve a descrição de todos os elementos resultantes do ambiente pedagógico e das relações estabelecidas entre esses elementos, e (iii) a disponibilização dos dados para a comunidade científica. Essas características permitem o compartilhamento e o reuso dos dados por diferentes pesquisadores análises cumulativas que podem fazer avançar o conhecimento e as discussões interdisciplinares sobre língua/linguagem, ensino-aprendizagem e uso de tecnologias.

Valdir Silva - Não se sei se devemos nos preocupar com tais distanciamentos ou aproximações. Para mim, as lacunas (as perguntas) são sempre da ordem do inacabado. Vejo essas lacunas como constitutivas da vastidão das práticas sociais, de pesquisa, em particular nas humanidades. Por isso, penso que é nosso papel como pesquisadores é pesquisar, pesquisar e...pesquisar.

Vilson Leffa - A proposta de desenvolver tutores automáticos é feita com uma ressalva: ninguém quer alunos interagindo com autômatos projetados para darem respostas totalmente previsíveis, resgatando para a espaço virtual o antigo paradigma da instrução programada, que sempre foi visto como pedagogicamente indesejável e às vezes até pernicioso, trazendo mais danos do que benefícios para a aprendizagem. O que sugiro é dar ao aluno andaimes, que propiciem 
pistas, corrigindo desvios e melhorando o aprendizado. Para isso, proponho fazer a diferença entre instrução programada tradicional, de base skinneriana, e andaimes, de base vygotskyana, que é a seguinte: (1) a instrução programa tradicional é rígida, direta e não se adapta automaticamente à mudanças de contextos, aos recursos disponíveis e às necessidades cambiantes dos alunos; (2) já os andaimes são flexíveis, mediacionais, adaptáveis e essencialmente responsivos a todos esses aspectos. Lá na instrução programada,

"Ninguém quer alunos interagindo com autômatos projetados para darem respostas totalmente previsíveis, resgatando para a espaço virtual o antigo paradigma da instrução programada, que sempre foi visto como pedagogicamente indesejável e às vezes até pernicioso, trazendo mais danos do que benefícios para a aprendizagem."

quando o aluno cometia um engano em seu desempenho, ele recebia um feedback explicando, com algum sucesso, qual era o problema; algo, já em si respeitável, por ser dado ao aluno no momento em que ele precisava de ajuda, mas era ainda um feedback com pouca chance de ser responsivo a seus interesses, por partir de um programa pré-elaborado, ao contrário dos andaimes, que são pós-elaborados, e partem das necessidades que vão surgindo ao longo do percurso. Não chega ao aluno como algo pronto; instancia-se responsivamente à medida que o desempenho vai acontecendo.

\section{LF - Em que os conhecimentos adquiridos com as pesquisas mencionadas ajudariam a área de Linguagem e Tecnologia, o professor, o aluno, enfim, o cidadão?}

Fabiana Komesu - Vivemos sob a ordem da transparência dos sentidos ou da busca incessante por essa transparência nas diferentes relações sociais atravessadas pela linguagem. Han (2017) trata o imperativo da transparência, da hiperexposição nas redes sociais, da positivação das relações humanas, como condição de uma violência que gera vigilância mútua. Esse imperativo da transparência dos sentidos se aplica também, numa direção um pouco diferente, à da transparência dos resultados de pesquisa, muito em voga na ênfase que se tem dado às pesquisas em ciências aplicadas, particularmente do ramo do chamado Movimento STEM (Science, Technology, Engineering, and Mathematics). Esse movimento, ou, mais precisamente, esse projeto, cada vez mais presente no ensino 
básico brasileiro, vem sendo inserido, nos últimos tempos, no contexto de outras determinações, declaradamente ideológicas, de rarefação ou mesmo supressão dos estudos relacionados às Humanidades. Vem com ele a ênfase na materialização em produtos (mercadorias?) e em sua utilização funcional do ponto de vista de sua utilidade social imediata. No campo das Humanidades, no qual, naturalmente, nos incluímos, o trabalho de compreensão dos processos históricos se faz de modo mais lento e não segue, portanto, o ritmo que aquele projeto idealiza, nem se dirige imediatamente para uma aplicação na sociedade, mas sim para a ação na sociedade por meio da intervenção de novas explicações inclusive sobre o que já é considerado como sabido. No que se refere à minha pesquisa, cito, como ilustração, a relevância do trabalho que venho desenvolvendo com as fake news. Martens et al. (2018) chamam a atenção, em relatório europeu, para o fato de que o termo fake news pode tanto ter uma concepção restrita - a que pode ser averiguada por agências de fact-checking, com a marcação de posts suspeitos, remoção de notícias falsas, dentre outras ações que temos visto mais recentemente no Brasil -, quanto uma concepção ampla - em que a "distorção" de informação serviria ao propósito deliberado de promover determinadas ideologias em detrimento de outras, semeando discórdia e fomentando polarização social e política. Em relatório da Comissão Europeia, o Independent High level Group on fake news and online disinformation afirma que "a ameaça é a desinformação, não as 'fake news'"

"Enfatiza-se fortemente a necessidade da discussão de letramentos digitais e midiáticos na formação cidadã. Acredito que aluno, professor, todo cidadão têm a ganhar com o reconhecimento dessas relações nada transparentes da linguagem."

(2018, p. 10 - tradução minha) no sentido restrito apresentado por Martens et al. (2018). O problema nasce justamente nesse ponto. Por um lado, na condição de usuário de tecnologia, a pessoa acredita que tem acesso ilimitado a informações, sem se dar conta de que coerções ideológicas a impedem de ler "tudo" que estaria disponível na rede; tem engajamento em mídias sociais, com forte descrença nas ciências e instituições tradicionais (McINTYRE, 2018); utiliza plataformas digitais e a elas entrega os dados que Ihe forem solicitados sem considerar que essas plataformas dependem dessa extração e comercialização de informações, da monetização de clickbaits, segundo uma governança algorítmica de reprodução de sistemas econômicos. É um "poder afável" da extração de dados das redes sociais, de que trata Han (2018), em outro trabalho. Por isso, parte das re- 
comendações de relatórios de instituições internacionais de combate a notícias falsas ou enganosas é voltada a instituições e a atores sociais comuns. Enfatiza-se fortemente a necessidade da discussão de letramentos digitais e midiáticos na formação cidadã. Acredito que aluno, professor, todo cidadão têm a ganhar com o reconhecimento dessas relações nada transparentes da linguagem. Por outro lado, recomendações como essas permitem voltar a uma das nossas preocupações de pesquisa. De que maneira buscar a informação precisa? Seria então o caso de tomar o caminho da transparência do sentido? Se o perigo é a desinformação - aquilo que é confuso, obscuro, sombrio -, alguém poderia argumentar que a solução seria essa, a informação... transparente. Esse raciocínio, conhecido há tempos na comunicação social e, em particular, na produção jornalística impressa, foi concretizado em manuais da redação (manuais de intenção?), mas, nem estes nem as matérias efetivamente publicadas nos jornais alcançaram outra objetividade que não a que se aproxima da síntese (transparência como efeito do que não é prolixo), nunca aquela que recusa a subjetividade (transparência como isenta de posicionamentos). Como se sabe, esse é um problema antigo que ainda gera discussões de toda ordem, inclusive acadêmicas. Se, nos jornais, os anunciantes e os poderes institucionais têm papel relevante na produção, o que dizer das fake news que parecem ser geradas a partir de cada internauta individualmente? Obviamente, há muita coisa a ser compreendida além da imediata recusa das fake news e de sua imputabilização a um indivíduo particular. Questões éticas, como a da forma justa de relação com o outro pela linguagem, são, talvez, aceitas sem delongas, mas também outras que, na linguagem, dialogam com o campo da história e da sociedade só lentamente podem ser desenredadas.

Kyria Finardi - Como coloquei acima, eu creio que a pandemia acelerou a migração de processos de ensino-aprendizado-uso de L2 para o mundo virtual e resta agora à pesquisa sobre linguagem e tecnologia se debruçar sobre o impacto dessa aceleração e migração na linguagem/tecnologia, bem como nas questões de como essa pesquisa pode informar a formação de professores para esse novo cenário.

Marcelo Buzato - Em primeiro lugar, pesquisar essas questões hoje é ajudar a definir o que conta como humano e, portanto, como humanidades, direitos humanos, humanização, desumano, anti-humano, etc. para além da tradição ilumi- 
nista, humanista-liberal, por vezes romântica, de ser humano e das visões deterministas e neutralistas da tecnologia. Isso porque tais visões já não nos permitem

"Aprender a escrever é aprender a arquitetar formas linguísticas de tal modo a agradar um algoritmo probabilisticamente." debater e influir seriamente nos rumos que estão sendo tomados na implantação de mecanismos de sensoriamento, previsão, programação, correlação, etc. destinados a pautar os nossos modos de ação no mundo pela linguagem ou, o que é mais assustador, que se arrogam capazes de "resolver o mundo" por caminhos que supostamente não dependam da linguagem - considerada imprecisa e traiçoeira - , ou que reduzam a linguagem a "comando" ou a "comunicação", extirpando-a de tudo aquilo que faz dela o lugar da consciência, da subjetividade, da resistência e, claro, das humanas. O professor e o aluno devem ser ajudados por IAs e métodos preditivos baseados em metadados de ensino e aprendizagem, é claro, mas alguém tem que pesquisar os modos pelos quais não se deixa o aluno entender que aprender a escrever é aprender a arquitetar formas linguísticas de tal modo a agradar um algoritmo probabilisticamente . O cidadão deve utilizar mídias sociais para se colocar como cidadão, mas alguém precisa pesquisar o modo como um cidadão racional é transformado num "influenciado" dogmático, qual o papel dos algoritmos e robôs nisso e como se ensina esse cidadão a ler e escrever não apenas os posts, mas os algoritmos, os modelos de negócio, o que há por trás das notificações, recomendações etc. para além da superfície textual e do contexto social humano apenas, o que implica entender as tecnologias como parceiras sociais e a nós mesmos como seres capazes de agir maquinicamente. Finalmente, penso que, se conseguirmos entender o sujeito, o sujeito aluno, o sujeito professor, o sujeito cidadão, como uma unidade ao mesmo tempo biológica e cibernética, material e informacional, natural e construída, estaremos abrindo espaço para novas pedagogias , novas formas de legislar e regulamentar tecnologias que tenham externali-

"Como se ensina esse cidadão a ler e escrever não apenas os posts, mas os algoritmos, os modelos de negócio, o que há por trás das notificações, recomendações etc. para além da superfície textual e do contexto social humano apenas, o que implica entender as tecnologias como parceiras sociais e a nós mesmos como seres capazes de agir maquinicamente."

dades imorais, assim como para melhorar o acesso de grupos marginalizados a 
espaços discursivos de decisão institucional e política. Mas isso apenas se conseguirmos nos capacitar para entender como funciona a hegemonia dos dados e do quantitativo, como se cria a impressão de que a imitação de um comportamento inteligente transforma o computador, para o interlocutor, em um ser inteligente e assim por diante. Se for assim, estaremos mais aptos a passar longe de utopias sobre imortalidade, eugenia baseada em edição genética, inteligência artificial no governo ou a "autonomia" dos números puros sobre as ciências causais (entre elas a linguística), mas também dos estereótipos de humanidade baseados num humanismo liberal que não dá mais conta de explicar nem mesmo por que os direitos humanos só valem para alguns humanos, ou por que as ciências humanas estão sob um ataque tão terrível em todos os países, isto é, sobre por que suas explicações parecem, aos olhos de certos gestores, não valer o salário pago a seus professores e pesquisadores. A meta final, claro, será entender o que há de oportunidade e o que há de ameaça nas maravilhas tecnológicas do nosso tempo, desde o nível da política científico-tecnológica em curso no país, até o nível das pequenas decisões que tomamos quando aceitamos ou recusamos coisas que nossos telefones, automóveis ou relógios nos pedem permissão para fazer conosco, enquanto achamos que apenas nós fazemos coisas com eles.

Raquel Recuero - Acho que podemos dar passos importantíssimos para compreender os fenômenos discursivos na mídia social, que têm sido explosivos no Brasil. Não só desinformação sobre o Covid, mas sobre saúde pública, vacinas, toxicidade e outras questões. Isso é importantíssimo, porque tem impactos na vida das pessoas, na cidadania, na própria democracia. Precisamos de muitas pesquisas sobre o assunto para avançarmos.

Roberta Caiado - Acredito que as pesquisas científicas na Era Pandêmica podem colaborar para o surgimento de uma rede criativa, reflexiva e crítica na Área de Linguagem e Tecnologia, principalmente relacionada ao ensino-aprendizagem, na qual, a partir da transposição dos saberes para o meio digital, o professor, o aluno e o cidadão partilhassem tempos de personalização, intensa colaboração e tutoria (MORAN, 20205).

Robson Oliveira - Através dos diversos livros, documentos norteadores do go-

5 Lives Aprendizagens: conversa com Educadores - José Moran (USP). Disponível em: <bit.ly/livesnehte>. Acesso em: 15 de jul. de 2020. 
verno federal, eventos acadêmicos e/ou formações de profissionais de educação por agências oficiais de ensino (secretarias municipais e estaduais de educação, MEC, etc.) assim como dos conteúdos e vivências pedagógicas vivenciadas nos cursos de graduação de licenciaturas e nas especializações específicas tem ocorrido contribuição na área de Linguagem e Tecnologia. Ao analisarmos, por exemplo, a BNCC (BRASIL, 2018), verificamos o expressivo contingente de termos e referências aos usos das tecnologias da educação, tais como podcasts, vlogs, hipertextualidade, games, vídeos e fotos, aplicativos digitais, redes sociais na internet etc. Podemos observar que as propostas, por exemplo, da Pedagogia dos Multiletramentos (GNL, 2000 [1996)] bem como as pesquisas e contribuições sobre multimodalidade (KRESS; VAN LEEUWEN, 2006; JEWITT, 2009) propõem resignificar muitas práticas pedagógicas, principalmente pelo uso das tecnologias digitais. E essas propostas não são apenas de uso pragmático de tecnologias em educação, mas de uma proposição crítico-reflexiva, estimulando uma prática transformadora a partir de situações pedagógicas, mediações docentes, pensar crítico por parte dos alunos. Não há como fugir do uso massivo das tecnologias cada dia em nossas vidas, no âmbito mais geral da sociedade, em todas as áreas; a escola não poderia ficar indene a este movimento sociocultural de tecnologias e mídias integradas. O uso de smartphones e da consequente mobile learning; as facilidades da internet e as formas variadas de ensino como Ensino a Distância (EaD), de ensino híbrido, de aula invertida, de robótica e gamificação nas escolas são realidades cada vez mais comuns. Assim, o estudo contínuo e as reflexões didático-pedagógicas das tecnologias educacionais ajudam e ajudarão cada vez mais os educadores, alunos, enfim, os cidadãos a fazerem uso consciente e cada vez mais crítico-reflexivo das tecnologias digitais da informação e da comunicação.

Rodrigo Aragão - Como apontei, avançamos e precisamos continuar seguindo em frente na luta contra as adversidades e desejando um mundo melhor. Vejo que o campo da formação de professores, da profissão docente, e da aprendizagem de línguas mediado pelas tecnologias digitais fortalecem nossa luta por democracia e por contínua manutenção do exercício pleno de nossa cidadania. Os conhecimentos que temos gerado nos indicam como a reflexão crítica sobre as práticas pedagógicas e sobre nossas relações com tecnologias digitais podem nos ajudar a projetar mundos melhores. Mudanças que envolvem inter-relações entre linguagem e tecnologias envolvem um denso campo de emoções que flui 
em rede com outros pontos do sistema. Essas transformações quando provocadas e sustentadas retroalimentam outros processos que podem levar a estabilização

"O potencial de tecnologias digitais para o ensino e aprendizagem de línguas não está propriamente nelas, mas, nas ações, emoções e redes de relações conjuntas e idealmente coletivas e colaborativas, que podem ser propiciadas com elas." das transformações ocorridas. $\bigcirc$ potencial de tecnologias digitais para o ensino e aprendizagem de línguas não está propriamente nelas, mas, nas ações, emoções e redes de relações conjuntas e idealmente coletivas e colaborativas, que podem ser propiciadas com elas. Tenho argumentado como nessa deriva atual mergulhada em desinformação, luto e dor, as políticas do medo se aprofundam. Por outro lado, a dor que sufoca deriva em luto que se que torna luta, reação e resistência. Aqui vemos o homo sapiens milenar ressurgir contra o sufocamento do patriarcalismo, demonstrando laços de solidariedade e luta contra o processo de extermínio de nós mesmos através de ódio. Processos mais focados nos protagonismos estudantis, na escola desejada e embasadas em uma educação para cidadania são alternativas para lidar com as crises que se aprofundam a partir dos modelos educacionais ainda vigentes. É urgente promovermos uma educação que articule emoção com razão, linguagem com tecnologias, e reflexão crítica. Os espaços educativos formais precisam sempre de ser domínios de convivência, baseadas no desejo mútuo de respeito e com fomento de laços de solidariedade.

Rodrigo Lopes - Em princípio acredito que precisamos caminhar por três searas importantes. A primeira estaria relacionada ao reconhecimento do papel da tecnologia nas relações humanas da contemporaneidade. É imperativo observar que as tecnologias são máquinas de significação social, ao passo que as diversas mídias são a expressão que os diferentes grupos sociais fazem dessas máquinas. Esse caminho dificilmente será trilhado se não deixar-

"As tecnologias são máquinas de significação social, ao passo que as diversas mídias são a expressão que os diferentes grupos sociais fazem dessas máquinas. Esse caminho dificilmente será trilhado se não deixarmos de lado o fascínio pelos processos tecnológicos." mos de lado o fascínio pelos processos tecnológicos. Isso significa observá-los não apenas pelo viés da inclusão e do acesso, ou pelo simples reconhecimento 
da existência de múltiplas linguagens, mas também observar o papel das diversas redes, dos algoritmos e dos potenciais discursos que neles há. Isso significa não pensar as diferentes tecnologias como elementos neutros e ascéticos. Assim como a linguagem carrega em si uma representação do mundo, refletindo ideologias, as demais tecnologias também o são. A segunda estaria ligada à formação de professores e pesquisadores. De maneira geral, os cursos de Letras precisam de reflexões sobre a realidade tecnológica que vivemos e do papel que a língua possui em tal contexto. É relevante observar que a aprendizagem de diferentes linguagens passa por uma discussão sobre sua estrutura e sobre sua função nas diferentes mídias, ao mesmo tempo que o uso das diversas mídias e tecnologias deve ser visto pela sua capacidade de representação e autorrepresentação. Buscar-se-ia, outrossim, letrar cidadãos para que sejam capazes de usar criticamente a tecnologia em seus contextos locais, valorizando sua cultura. Para que isso ocorra, é imprescindível abrir a caixa de pandora, tornando as diferentes linguagens menos opacas. A terceira seria referente ao reconhecimento de que a pesquisa deve ir além daquilo que nos é visível em um nível mais superficial de interação com a tecnologia. Para isso, deve haver uma instrumentalização do pesquisador para lidar com processos de extração e representação de dados em grande escala, de forma a buscar compreender as diferentes práticas de linguagem, seu papel ideológico, e a influência que os diversos algoritmos impõem. É imprescindivel observar que a análise desses dados também é apenas uma entre as possíveis formas de encarar o fenômeno, todavia acredito que seja a que mais estejamos deficitários. Outro ponto importante é refletir sobre a importância do uso de tecnologias abertas no ambiente acadêmico e educacional de maneira geral, incentivando processos de cooperação e desenvolvimento local. Um exemplo dessa necessidade está nas próprias revistas acadêmicas em nossa área, que, na maioria dos casos, solicitam envio de arquivos de texto em extensões geradas por processadores de texto comerciais e proprietários.

Suzi Cavalari - A relação estabelecida com as tecnologias a partir da pandemia da Covid-19 terá impacto duradouro em todas esferas da vida, inclusive na educação de línguas. Nesse sentido, compreender os detalhes singulares assim como os elementos generalizáveis dos processos de ensino-aprendizagem em contextos mediados por tecnologias poderá trazer benefícios a todos os atores envolvidos: professores, alunos, gestores escolares. Além disso, tal perspectiva aberta do fazer científico, em que princípios de compartilhamento (de dados, de metodologias, 
de resultados) e de colaboração entre pesquisadores são fundamentais, pode trazer contribuições para os processos de internacionalização, para o desenvolvimento de políticas de educação linguística, e para a formação dos professores de línguas. De fato, resultados alcançados até o momento por meio do intercâmbio entre grupos de pesquisadores tem, na prática, levado à crescente integração de práticas telecolaborativas ao curriculum e às políticas institucionais tanto no contexto brasileiro quanto no exterior.

Valdir Silva - Os conhecimentos gerados pelas pesquisas sobre Linguagem e Tecnologia são fundamentais para se compreender as dinâmicas dos processos

"A histórica negligência de governos e de instituições formadoras marcadamente extemporâneas, contribuíram, por exemplo, para o inferno que se transformou a vida de professores e alunos das escolas públicas, em particular, devido ao afastamento social imposto pela Covid-19 e instituindo o trabalho remoto." de interação social mediados pela linguagem e midiatizados pelas tecnologias digitais. Dada a importância das tecnologias em todas as esferas da sociedade contemporânea, tais pesquisas precisam ter maior consequência, principalmente para as práticas de ensino. Para tanto, tais pesquisas precisam receber maior atenção e investimentos dos órgãos de fomento nacional e estadual. Tais pesquisas precisam reverberar fortemente nas universidades, em particular nos cursos de licenciaturas, para que elas, urgentemente, se atualizem e se conectem com as novas demandas da realidade do mundo atual e futuro. Nessa mesma direção - com o apoio dos governos e universidades - as escolas e suas práticas também precisam ser ressignificadas. A histórica negligência de governos e de instituições formadoras marcadamente extemporâneas, contribuíram, por exemplo, para o inferno que se transformou a vida de professores e alunos das escolas públicas, em particular, devido ao afastamento social imposto pela Covid-19 e instituindo o trabalho remoto. Em outros termos, se as práticas de Linguagem, Tecnologia e Ensino fossem constitutivas das rotinas dessas instituições, provavelmente esse pandemônio escolar seriam bem menos sofríveis. Eu creio que, se de fato o digital se instituir, não só agora, mas também no mundo pós-pandemia, como diz Manuel Castells, nós pesquisadores da área da Linguagem e Tecnologia e Ensino, vamos ter muito mais trabalho pela frente. 
Vilson Leffa - A educação volta-se ao mesmo tempo para o passado e para o futuro, enfrentando o paradoxo de precisar inovar quando acreditamos, desde Salomão, que nada há de novo sob o sol. Como inovar se tudo o que puder ser feito já foi feito? Se tudo o que puder ser dito já foi dito? Há duas hipóteses para contornar este paradoxo. A primeira é de que o conhecimento está distribuído de modo desigual na humanidade e que a missão do professor é redistribuir esse conhecimento, dando ao aluno o que ele não sabe, o que para ele é novidade, repetindo o que já foi dito até que seja ouvido. Essa é a hipótese

"Inovar é fazer o que já foi feito, mas que precisa ser feito de modo diferente, aproveitando os novos andaimes oferecidos pela tecnologia digital, incluindo computadores, tablets, smartphones e seus aplicativos" menos interessante: encher a cabeça do aluno. A segunda, mais interessante, é de que inovar é fazer o que já foi feito, mas que precisa ser feito de modo diferente, aproveitando os novos andaimes oferecidos pela tecnologia digital, incluindo computadores, tablets, smartphones e seus aplicativos. A diferença está em usar essa tecnologia não como mediação entre professor e aluno, como se fazia com as apostilas impressas em papel, mas como agência, como é possível fazer agora com os recursos educacionais digitais, que podem atuar ao lado do professor, não apenas como tutores, mas como tutores responsivos, capazes de atuar em três instâncias de responsivida-

"Para a educação, podemos cruzar os dados do histórico do aluno com os dados relevantes da internet e oferecer a ele um andaime adequado à altura de seu conhecimento ." de: (1) responsivos aos diferentes suportes digitais disponíveis aos alunos, entre os quais, certamente, está o celular; (2) responsivos a objetivos que sejam relevantes ao ensino da língua, seja na dimensão sistêmica, seja na dimensão comunicativa, seja na dimensão crítica; (3) e principalmente responsivos aos interesses e necessidades dos alunos, propiciando de modo automático as pistas e andaimes adequados a seu estilo e nível de aprendizagem, como já é feito, por exemplo, na publicidade virtual, com o uso de big data e de algoritmos que preveem os desejos de consumo do usuário da internet para mostrar os anúncios que lhe são relevantes. O que falta é trazer esses algoritmos para a educação. Estamos a um passo de criar avatares com feições, voz e atitudes indistinguíveis de um ser humano, capazes de atuar como assistentes pessoais, como acontece de modo fantástico no filme Ela, de 2013, em 
que o avatar é um recurso de fachada para dar vida às enormes bases de dados já disponíveis na internet e oferecer ao espectador uma fantasiosa história de amor. Para a educação, podemos cruzar os dados do histórico do aluno com os dados relevantes da internet e oferecer a ele um andaime adequado à altura de seu conhecimento. Obviamente há questões delicadas de privacidade a serem resolvidas aqui - como também é óbvio que a tecnologia assumirá um papel cada vez maior na educação, o que nos obriga a estar preparados para usá-la. Vamos sonhar que faremos a tecnologia trabalhar mais para nós, sem a criação de escravos e mestres, mas em uma perspectiva de integração e de agência distribuída com as máquinas para que possamos saber mais, fazer mais, ser mais, em suma, até conseguirmos agir acima de nossa competência.

\section{Algumas Referências}

BRIDLE, J. A nova idade das trevas: A tecnologia e o fim do futuro. São Paulo: Todavia, 2019.

EUROPEAN COMMISSION. A multi-dimensional approach to disinformation. Report of the independente High level Group on fake news and online disinformation. Luxembourg; Publications Office of the European Union, 2018. Disponível em: https://ec.europa.eu/digital-single-market/en/news/final-report-high-level-expert- group-fake-news-and-online-disinformation. Acesso em: 30 jul.2020.

FLUSSER, V. O mundo codificado. São Paulo: Cosac Naif, 2007.

FLUSSER, V. A escrita: há futuro para a escrita?. São Paulo: Annablume, 2010.

HAN, B.-C. Psicopolítica. Trad.: Maurício Liesen. Veneza, Itália: Âyiné, 2018.

HAN, B.-C. Sociedade da transparência. Trad.: Enio Giachini. Rio de Janeiro: Editora Vozes, 2017.

HOFFMAN, D. S. The Web of Hate: Extremists Exploit the Internet. 1996.

KRESS, G. Against Arbitrariness: The Social Production of the Sign as a Foundational Issue in Critical Discourse Analysis. Discourse \& Society. 1993. 4(2), 169-191. https://doi.org/10.1177/0957926 593004002003.

KOMESU, F.; GALLI, F. C. S. Práticas de leitura e escrita em contexto digital: autoria e(m) novos mídiuns. Revista da ABRALIN, v.15, p.165-185, 2016.

LÉVY, P. A revolução contemporânea em matéria de comunicação. A Revolução Contemporânea Em Matéria de Comunicação. 1998. 9, 37-49. https://doi.org/10.15448/1980-3729.1998.9.3009.

MARTENS, B. et al. The digital transformation of new media and the rise of disinformation and fake news - an economic perspective. Seville: European Commission, Joint Research Centre, 2018. Disponível em: https://ec.europa.eu/jrc/en/publication/eur-scientific-and-technical-research-reports/digital-transformation-news-media-and-rise-disinformation-and-fake-news. Acesso em: 30 jul.2020. 
McINTYRE, L. Post-truth. Cambridge, MA: The MIT Press, 2018.

MOROZOV, E. A cidade inteligente: Tecnologias urbanas e democracia. São Paulo: Ubu Editora, 2019.

NOBLE, S. U. Algorithms of oppression: How search engines reinforce racism. New York: NYU Press, 2018.

RIEDER, B. Engines of order: A mechanology of algorithmic techniques. Amsterdam: Amsterdam University Press, 2020.

\section{Sobre os autores}

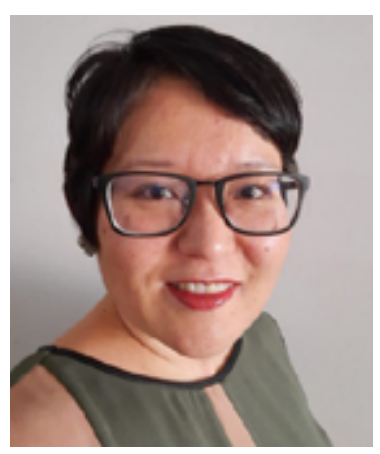

Fabiana Cristina Komesu - É docente e pesquisadora do Departamento de Estudos Linguísticos e Literários da Universidade Estadual Paulista (Unesp), campus de São José do Rio Preto e do Programa de Pós-graduação em Estudos Linguísticos da mesma Instituição. É doutora em Linguística pela Universidade Estadual de Campinas (Unicamp, 2005), tendo realizado estágio no exterior na Université de Paris XII, França (2002-2003). Fez pós-doutorado em Linguística Aplicada na Universidade de São Paulo (USP). Atualmente, é coordenadora de rede internacional de pesquisa Literacies in Different Fields of Knowledge e membro pesquisador de projeto Universal/ CNPq (2019-em andamento). E-mail: fabiana.komesu@unesp.br

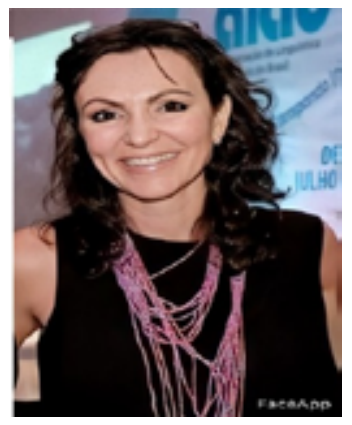

Kyria Rebeca Finardi - Doutora em Letras pela Universidade Federal de Santa Catarina com estágio pós-doutoral realizado na Universidade de Genebra. Professora da Universidade Federal do Espírito Santo (UFES) no Departamento de Linguagens, Cultura e Educação do Centro de Educação e membro permanente dos Programas de pós-graduação em Linguística na linha de Linguística Aplicada (PPGEL) e em Educação na Linha de Educação e Linguagens (PPGE). Bolsista de Produtividade em Pesquisa Cnpq (PQ). E-mail: kyria.

finardi@gmail.com

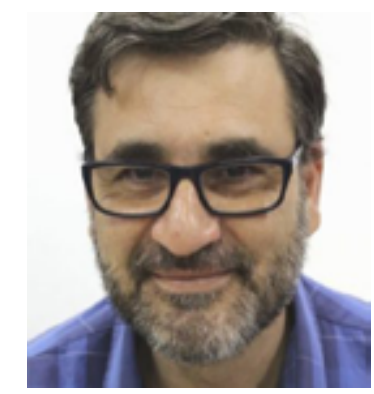

Marcelo El Khouri Buzato - Doutor em Linguística Aplicada pela Universidade Estadual de Campinas, com estágio pósdoutoral realizado na Universidade da Califórnia. Professor livre-docente e coordenador do Programa de Pós-graduação em Linguística Aplicada da Universidade Estadual de Campinas. Participa do GT Linguagem e Tecnologias da ANPOLL. Coordena o grupo de pesquisa Linguagem, Tecnologias e Pós-humanidade/sociedade, do CNPq. E-mail: marcelo.buzato@gmail.com 


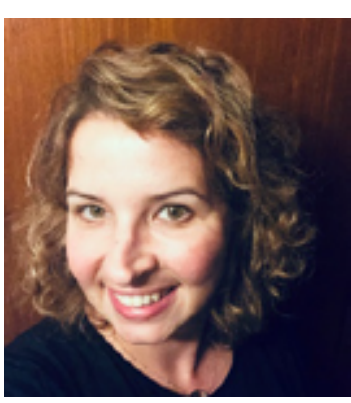

gmail.com

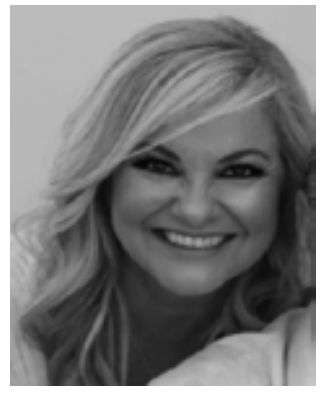

roberta@gmail.com

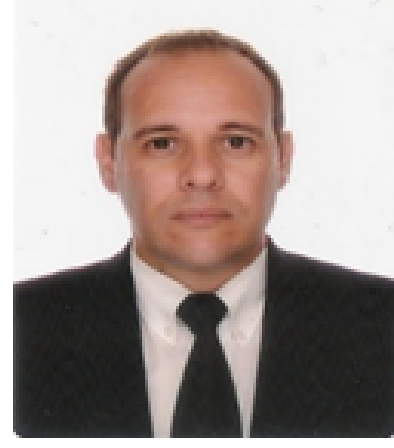

Robson Santos de Oliveira - Doutor em Psicologia Cognitiva pela Universidade Federal de Pernambuco com estágio de pós-doutoral pela Universidade Federal do Ceará. Professor adjunto na Universidade Federal Rural de Pernambuco (UFRPE) na área de Ciência da Computação e do programa de Mestrado Profissional em Letras (Profletras) das Universidades de Pernambuco (UPE) e UFRPE/UAG, com orientações desenvolvidas na área de multimodalidade e tecnologias educacionais. E-mail: robssantoss@yahoo.com.br

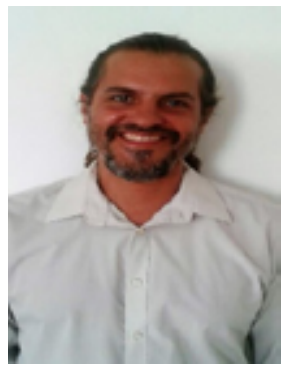

Rodrigo Camargo Aragão - Doutor em Linguística (UFMG) com estágio na Universidade de Sevilha. Fez o estágio pósdoutoral na UFMG e na Universidade de Jyväskylä. Atua nos Programas de Pós-graduação e Licenciatura em Letras da Universidade Estadual de Santa Cruz (UESC). Pesquisa linguagens, tecnologias e emoções em experiências de ensino e aprendizagem de línguas. Tem interesse em desdobramentos da cibernética e do pensamento sistêmico de Maturana para compreensão de inter-relações entre linguagem, cognição e cultura. E-mail: aragaorc@gmail.com 


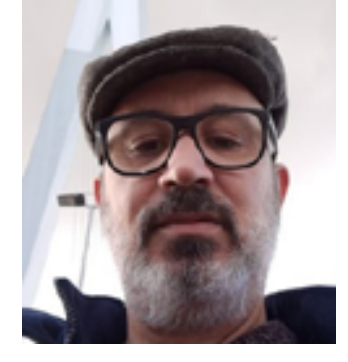

Rodrigo Esteves de Lima Lopes - Doutorado em Linguística Aplicada pelo IEL/Unicamp. Professor da Universidade Estadual de Campinas no Instituto de Estudos da Linguagem (IEL) e Departamento de Linguística Aplicada (DLA), atuando na graduação e na pós-graduação. É coordenador do GT de Linguagens e Tecnologias da ANPOLL e vice-presidente da Associação de Linguística Sistêmico-Funcional da América Latina (ALSFAL). E-mail: rll307@unicamp.br

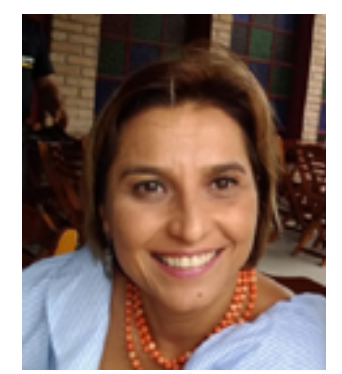

Suzi Marques Spatti Cavalari - Doutora em Estudos Linguísticos pela Universidade Estadual Paulista Júlio de Mesquita Filho (UNESP). Professora de língua inglesa da UNESP. Na pósgraduação, atua na área de Linguística Aplicada, linha de Ensino e Aprendizagem de Línguas, enfocando principalmente os seguintes temas: aprendizagem em teletandem, autonomia e avaliação. E-mail: suzi.cavalari@unesp.br

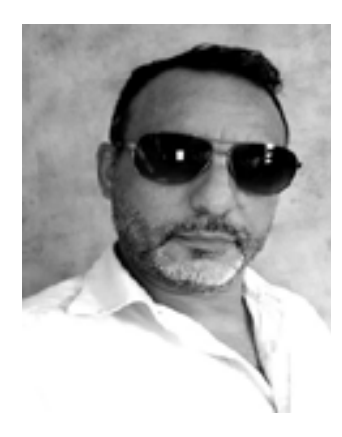

Valdir Silva - Doutor em Linguística Aplicada pela Faculdade de Letras (FALE/UFMG). Professor do Programa de PósGraduação em Linguística da Universidade do Estado do Mato Grosso. (UNEMAT) e do mestrado Interinstitucional em Letras. Líder do Grupo de Pesquisa/CNPq Linguagem, Tecnologia e Contemporaneidade em Linguística Aplicada (LINTECLA) e do projeto "Linguagem, redes sociais e dispositivos móveis: resiliência e adaptações nas práticas de ensino e de aprendizagem contemporâneas". E-mail: ollule4@yahoo.com

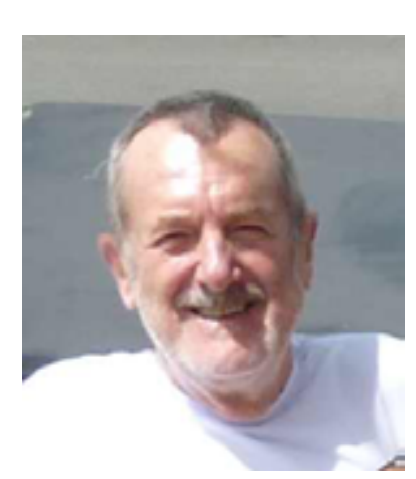

Vilson Leffa - PhD em Linguística Aplicada. Doutorou-se em Linguística Aplicada pela Universidade do Texas, trabalhou na Universidade Federal do Rio Grande do Sul, na Universidade Católica de Pelotas, foi pesquisador visitante da Universidade da Califórnia, em Irvine e da Universidade Federal de Pelotas. Foi duas vezes presidente da Associação de Linguística Aplicada do Brasil (ALAB), atuou como coordenador da área de Artes e Letras na FAPERGS. Foi avaliador do Plano Nacional do Livro Didático em língua estrangeira, coordenador do GT de Linguística Aplicada da ANPOLL, líder de grupo de pesquisa do CNPq. Criou o Periódico Linguagem e Ensino. E-mail: leffav@gmail.com 